\title{
KAJIAN ARSITEKTUR VERNAKULAR (RUANG DAN STRUKTUR) LAMPUNG. DESA PEKON HUJUNG LAMPUNG
} BARAT

\author{
Adelia Enjelina Matondang ${ }^{1, *}$, A. Asrul Sani ${ }^{2}$, Guruh Kristiadi Kurniawan ${ }^{3}$ \\ ${ }_{1}^{1}$ Prodi Arsitektur, Jurusan Infrastruktur dan Kewilayahan, ITERA, Lampung Selatan, 35365 \\ 2 Prodi Arsitektur, Jurusan Infrastruktur dan Kewilayahan, ITERA, Lampung Selatan, 35365 \\ ${ }^{3}$ Prodi Arsitektur, Jurusan Infrastruktur dan Kewilayahan, ITERA, Lampung Selatan, 35365 \\ adelia.matondang@ar.itera.ac.id
}

\begin{abstract}
ABSTRAK
Arsitektur vernakular Lampung saat ini masih dapat ditemui dibeberapa daerah di Lampung. Seiring dengan perkembangan jaman jumlah bangunan tradisional ini semakin lama semakin berkurang. Mulai dari alasan tidak lagi mampu menampung kegiatan manusia modern juga karena dianggap kuno yang menjadi faktor utama menghilangnya bangunan tradisional ini. Desa Pekon Hujung merupakan salah satu daerah yang berada di Kecamatan Belalau, Lampung Barat. Desa ini dipilih menjadi lokasi penelitian karena desa ini masih memiliki bangunan vernakular Lampung yang usianya sudah mencapai ratusan tahun. Arsitektur vernakular Lampung merupakan warisan leluhur budaya yang akan sulit ditemukan lagi di lingkungan masyarakatnya. Penelitian ini bertujuan untuk menganalisa arsitektur vernakular Lampung dengan lokasi penelitian di Desa Pekon Hujung. Arsitektur vernakular Desa Pekon Hujung merupakan gambaran mengenai bentuk, denah, tata ruang yang tercermin melalui kebudayaan masyarakat Desa Pekon Hujung terhadap lingkungan alam dan sosialnya. Penelitian ini menggunakan pendekatan kualitatif. Hasil dari penelitian ini bertujuan untuk memberikan pemahaman tentang telaah budaya menghuni dalam konteks hunian tradisional guna memberikan kesadaran bagi arsitek, pemilik, pengguna, dan pemerintah untuk mempertimbangkan kearifan budaya sebagai bagian dalam setiap keputusan desain yang diambil, baik dari sisi kekhasan maupun dari sisi keaslian.
\end{abstract}

Kata kunci : arsitektur tradisional, pekon hujung, vernakular

\section{ABSTRACT}

Lampung vernacular architecture can still be found in several areas in Lampung. Along with the changing times, the number of traditional buildings is decreasing. Starting from that reason is no longer able to accommodate modern human activities also because it is considered ancient which are the main factors of the disappearance of this traditional building. Pekon Hujung Village is an area in Belalau Regency, West Lampung. This village was chosen as a research location 
because it still has vernacular buildings in Lampung that are hundreds of years old. This study aims to analyze the vernacular architecture of Pekon Hujung Village is a description of the form, plan, and spatial structure that is reflected through the culture of the Pekon Hujung Village community in its natural and social environment. This research uses a qualitative approach. The results of this study aim to provide an understanding of the study of culture that inhabits in the context of traditional housing to provide awareness for architects, owners, users, and governments to consider cultural wisdom as part of every design decision taken, both in terms of uniqueness and in terms of authenticity.

Keywords: pekon hujung, tradisional housing, vernacular

\section{PENDAHULUAN}

Kajian arsitektur vernakular nusantara merupakan topik yang sangat urgen saat ini sebagai bentuk perhatian terhadap mulai menghilangnya nilai-nilai identitas di setiap wialayah budaya di Indonesia dari pengaruh arsitektur global. Arsitektur vernakular Lampung saat ini masih dapat ditemui dibeberapa daerah di Lampung. Seiring dengan perkembangan jaman jumlah bangunan tradisional ini semakin lama semakin berkurang dan mengalami perubahan dan perkembangan. Mulai dari dianggap tidak lagi mampu menampung kegiatan manusia saat ini juga karena dianggap kuno.

Desa Pekon Hujung merupakan salah satu daerah yang berada di Kecamatan Belalau, Lampung Barat. Desa ini dipilih menjadi lokasi penelitian karena desa ini masih memiliki bangunan tradisional Lampung yang usianya sudah mencapai ratusan tahun. Arsitektur vernakular Lampung merupakan warisan leluhur budaya yang akan sulit ditemukan lagi di lingkungan masyarakatnya. Selain ahli warisnya tidak merasa memiliki tradisi ini karena tidak pernah mempelajari kekayaan nilai yang melatarbelakangi pembangunannya, juga disebabkan faktor domestik terkait pemenuhan kebutuhan hidup sehari-hari. Kemiskinan masyarakat adat di perkampungan-perkampungan negeri (kampung asli masyarakat adat Lampung), berimplikasi terhadap upaya mereka untuk melestarikan tradisi-tradisi warisan leluhur budayanya. Penelitian ini bertujuan untuk menganalisa arsitektur vernakular Lampung di Desa Pekon Hujung. Arsitektur vernakular Desa Pekon Hujung merupakan gambaran mengenai bentuk, denah, tata ruang yang tercermin melalui kebudayaan masyarakat Desa Pekon Hujung terhadap lingkungan alam dan sosialnya. Elemen yang diteliti dari arsitektur tersebut adalah kajian elemen sambungan dan struktur bangunan.

\section{TINJAUAN PUSTAKA}

Menurut Sumalyo (1993) vernakular dalam arsitektur adalah istilah yang digunakan untuk menyebut bentuk-bentuk yang menerapkan unsur-unsur budaya, lingkungan termasuk iklim setempat, diungkapkan dalam bentuk fisik arsitektural (tata letak denah, struktur, detaildetail bagian, ornamen, dll). Arsitektur vernakular adalah desain arsitektur yang 
menyesuaikan iklim lokal, menggunakan teknik dan material lokal, dipengaruhi aspek sosial, budaya, dan ekonomi masyarakat setempat.

Beberapa konsep terkait hunian yang dihasilkan dan sering dirujuk oleh para peneliti arsitektur dalam memahami konsep-konsep hunian antara lain sociocultural factors (Morgan, 1981; Junianto, 2018) yang termasuk bentuk rumah (vernakular) sangat berkaitan dengan pola perilaku budaya, nilai-nilai budaya, dan sudut pandang terhadap dunia mereka. Simbol merupakan salah satu dari wujud kerangka pemikiran manusia danmasyarakatnya terhadap keberadaan semesta dan Penciptanya (Pangarsa et al., 2012). Memaknai berarti mengenal, mengetahui, memahami dan mengerti lingkungan atau ruang hunian hidupnya. Dengan demikian, simbol dan makna terkait sangat erat, sebagaimana dua sisi mata uang, pembahasan terhadap simbol tidak dapat dipisahkan dengan pembahasan terhadap makna yang dikandungnya. Dalam arsitektur ruang kota,sistem simbol seringkali merupakan bagian dari politik kebudayaan sebuah bangsa karenaselalu terkait dengan makna (pesan-pesan) tertentu yang ingin disampaikan negara melalui bangunan dan artefak fisik di dalam ruang kota. Syarief (2017) membagi konsepsi arsitektur Lampung berdasarkan bahan, konstruksi, struktur, bentuk, serta unsur bangunan dan ragam hias. Elemen-elemen tersebut akan digunakan sebagai dasar awal dalam penelitian rumah tradisional yang ada di Desa Pekon Hujung.

\section{METODOLOGI PENELITIAN}

Metode penelitian yang digunakan dalam penelitian ini adalah metode analisa kualitatif, berupa pemaparan kondisi objek yang diperoleh dari data primer dan data sekunder sehingga karakteristik arsitektur vernakular dan perkembangan sejarahnya teridentifikasi. Metode penelitian diawali dengan melakukan pengukuran pada bangunan tradisonal Lampung, kemudian diikuti dengan penggambaran model 3D dengan menggunakan software untuk menganalisa komposisi ruang dan bentuk. Selanjutnya penelitian akan dilanjutkan untuk menganalisa organisasi ruang, kualitas ruang, penggunaan ruang (penggunaan sehari-hari dan saat ada hajatan) dan kajian perubahan bentuk dan tata ruang sebagai implementasi perubahan budaya.

Berikut tahapan pengumpulan data :

1. Tahapan Persiapan

Kegiatan pada tahap persiapan yaitu studi literatur awal untuk proposal penelitian, penyusunan daftar pertanyaan wawancara, pengumpulan informasi terkaitan topik penelitian, dan menentukan kebutuhan alat untuk penelitian.

2. Tahapan Pengumpulan dan Klasifikasi Data.

Data primer merupakan data pokok yang didapat langsung dari objek penelitian berupa data kualitatif yaitu data yang tidak diukur secara nominal (data fisik 
permukiman, yang meliputi karakter visual dan karakter spasial). Data sekunder merupakan data pelengkap yang berisi hal-hal yang dapat mendukung dan berhubungan dengan data primer, berfungsi sebagai bahan arahan dan pertimbangan dalam proses komparasi. Peneliti mendatangi situs perkampungan tradisional yang masih ada, melakukan pemotretan dan pengukuran terhadap objek yang diteliti, serta melakukan wawancara terhadap orang-orang tua yang masih mengetahui seluk-beluk arsitektur tradisional tersebut. Data penelitian berupa fotofoto, sketsa dan hasil wawancara, dianalisis secara tipologi, diinterpretasi, serta dibandingkan dengan literatur yang sudah ada, dinarasikan secara kualitatif dan disusun dalam bentuk buku laporan penelitian kegiatan pada tahap ini terdiri dari studi literatur, observasi lapang (pemotretan, pengukuran, dan plotting elemen permukiman), dan wawancara.

\section{HASIL PENELITIAN DAN PEMBAHASAN}

Desa Pekon Hujung merupakan pekon yang terbentuk pada tahun 1973. Jauh sebelum berdirinya desa ini awalnya terdapat Pekon Tuha namun pada tahun 1950 an penduduk pindah ke Pekon Ginting/Pekon Geting yang artinya waswas. Setelah itu terbentuklah Pekon Bumi Agung dan kemudian Pekon Tipik yang artinya ditinggal. Barulah pada tahun 1973, Pekon Hujung dan Pekon Luas terbentuk. Desa Pekon Hujung merupakan sebuah desa yang berada di Kecamatan Belalau Lampung Barat dengan dengan kondisi udara relatif lebih dingin berada pada kisaran 20 sampai 24 derajat Celsius. Rumah tradisional yang diteliti merupakan rumah yang berada di Desa Pekon Hujung dan sudah dihuni selama lima generasi. Rumah tradisonal yang tersisa hanya empat rumah, dua rumah masih dengan kondisi atap menggunakan penutup atap ijuk dan dua rumah sudah berganti dengan penutup atap dari seng.

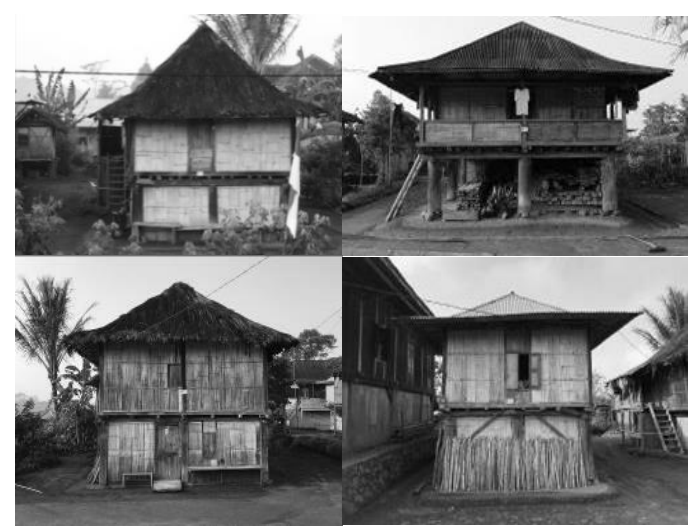

Gambar 1. Rumah Tradisional di Pekon Hujung

Rumah tradisonal yang tersisa masih dihuni oleh penduduk asli yang penghasilan utamanya dari berkebun kopi. dan masih berfungsi dengan baik walaupun sudah dihuni oleh lima 
generasi. Rumah yang masih menggunakan penutup atap ijuk memang rawan bocor dan dari wawancara dengan penghuni mereka berencana mengganti dengan penutup atap dari metal karena saat ini kesulitan untuk menemukan atap yang terbuat dari ijuk, dan juga penutup atap ijuk lebih cepat bocor dan kondisi ruang dalam rumah cenderung lembab.

\section{Susunan Ruang Dalam}

Bentukan dasar denah rumah pada awalnya berbentuk persegi. Pembangunan rumah biasanya dilakukan bertahap dan kemudian mengalami penambahan kebelakang atau kedepan atau kesamping. Penambahan ini yang akhirnya membentuk pola denah menjadi persegi panjang dan berbentuk L atau T. Penambahan didasarkan pada kebutuhan ruang yang diakibatkan oleh bertambahnya penghuni dalam rumah.

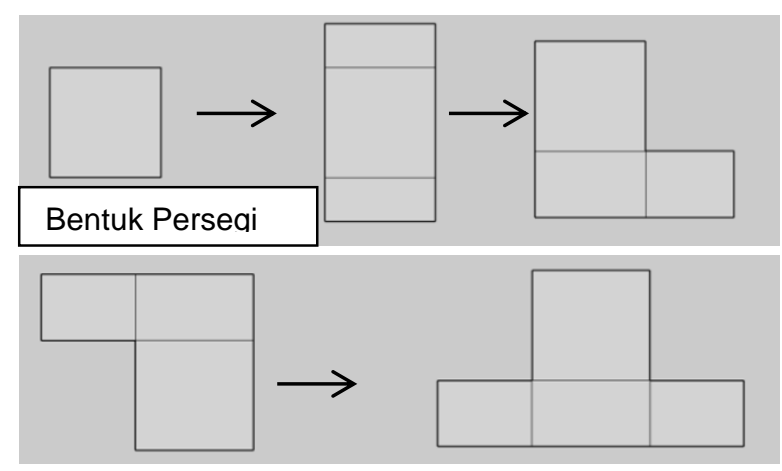

Gambar 2. Perubahan Bentukan Ruang Rumah

Bentuk massa awal yang berupa persegi yang merupakan dasar penyebutan rumah tradisional menjadi Lamban Pesagi. Perubahan bentuk massa utama juga mempengaruhi perubahan bentuk atap yang dasarnya berbentuk lancip. Selain diakibatkan oleh penambahan bentuk dikarenakan penambahan penghuni, perubahan bentuk massa utama juga dipengaruhi oleh sistem pembangunan bertahap diakibatkan kemampuan ekonomi pemilik rumah.

Berdasarkan hasil wawancara dengan kepala pekon ditemukan bahwa bentukan atap limas merupakan bentukan awal yang dibuat oleh nenek moyang beliau. Bentukan atap yang berbeda dengan bentukan awal atap yang sebelum-sebelumnya, menjadikan nenek moyang beliau didenda tujuh kwintal kopi karena membuat bentukan atap yang berbeda. Seiring dengan perkembangan perubahan denah akibat kebutuhan raung yang meningkat, mengakibatkan atap rumah tardisional yang ada menjadi berbentuk limas. 


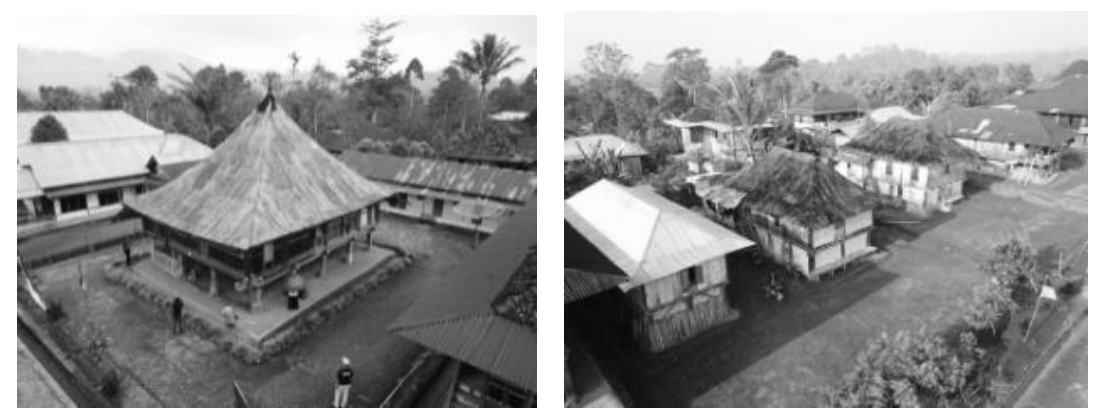

Gambar 3. Atap Lancip dan Atap Limas

Pembagian rumah dimulai dari beranda yang berada di sisi depan rumah. Beranda biasanya digunakan sebagai tempat untuk melaksanakan acara pernikahan dan acara khitanan. Setelah itu terdapat ruang tidur yang diperuntukkan untuk lajang sehingga disebut sebagai kamar lajang. Kamar ini juga digunakan oleh pengantin baru selama seminggu setelah pernikahan, kemudian setelah itu akan pindah ke kamar utama yang ada di tengah ruangan. Kamar tengah merupakan kamar utama untuk orang tua pemilik rumah dan anak tertua pemilik rumah setelah menikah. Pada ruang antara kamar utama biasanya digunakan oleh anak kecil dan remaja untuk duduk saat ada tamu atau ada acara dirumah tersebut.

Bagian tengah rumah merupakan inti ruangan sebagai tempat berkumpul didalam ruangan. Pada bagaian tengah rumah terdapat kolom utama yang disebut Sangai Batin. Saat ada tamu atau ada acara didalam rumah maka pemilik rumah akan duduk di dekat kolom Sangai Batin. Tangga berada disisi kanan rumah karena menurut tradisi jaman dulu posisi tetua pemilik rumah berada pada sisi kiri rumah sehingga tamu masuk kedalam rumah melalui sisi kanan. Sisi kiri rumah lebih diperuntukkan untuk usia yang lebih tua sedangkan usia yang lebih muda berada pada sisi kanan rumah.

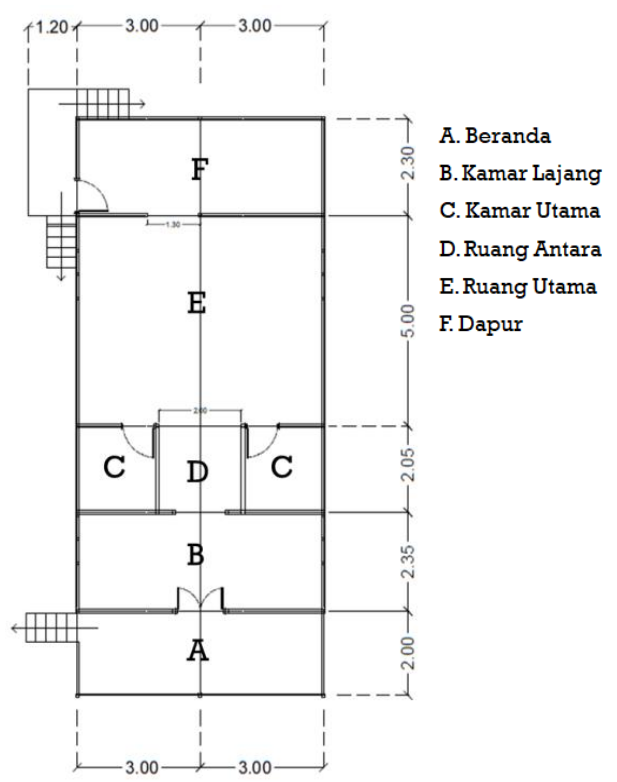

Gambar 4. Denah Ruang Rumah Tradisional Pekon Hujung 
Pada bagian ruang dalam rumah secara keseluruhan terkesan gelap dan lembap akibat tidak terlalu banyak bukaan. Hal ini diakibatkan oleh hanya terdapat beberapa jendela kecil yang dapat memasukkan cahaya disiang hari. Pemberian bukaan yang tidak terlalu banyak juga didasari oleh suhu didaerah tersebut yang relatif dingin.
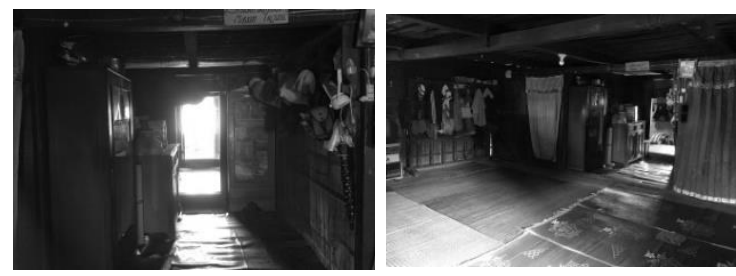

Gambar 5. Suasana Ruang Dalam

Dapur masih menggunakan tungku api. Pada bagian ruang tengah dan dapur diberi dinding tetapi tidak menutup sampai atas. Terdapat celah untuk melihat dari ruang tengah kedapur. Sistem dinding ini sudah digunakan sejak dahulu, hal ini sekarang banyak digunakan pada desain interior antara ruang tengah dan dapur.

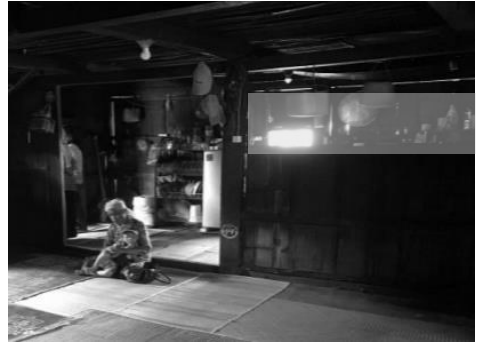

\section{Gambar 6. Detail Celah Dinding Pemisah Dapur Dengan Ruang Tengah}

\section{Struktur dan Konstruksi Ruang}

Sistem struktur Rumah tradisional Pekon Hujung menggunakan sistem struktur meja. Setiap kolom diikat kuat dengan balok sehingga struktur kaku. Ketika terjadi gempa maka keseluruhan struktur akan berpindah atau bergeser dari umpak. Setelah itu kemudian rumah dapat dikembalikan lagi ke atas umpak.

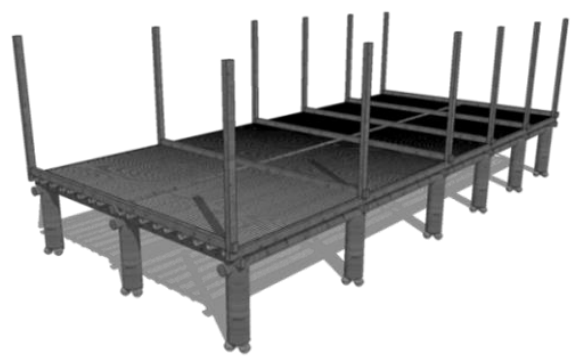

\section{Gambar 7. Struktur dan Konstruksi Ruang Dalam}

Pada awalnya konstruksi rumah panggung menggunakan umpak yang relatif tinggi namun seiring perjalanannya ketinggian umpak semakin rendah bahkan sekarang hanya ditaruh 
diatas beberapa bongkahan batu saja. Jika terjadi gempa maka kolom hanya bergeser saja dari atas bongkahan batu.

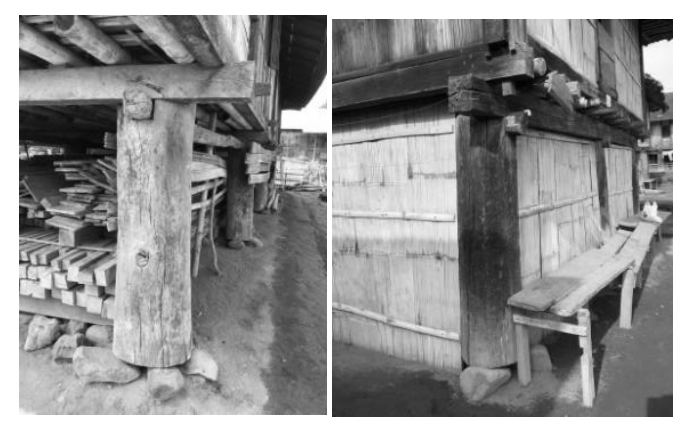

\section{Gambar 8. Detail sambungan umpak dengan tanah}

Konstruksi rumah menggunakan sistem pasak tanpa paku. Sambungan kolom dan balok menggunakan sistem melubangi kayu yang kemudian diperkuat dengan menggunakan pasak.

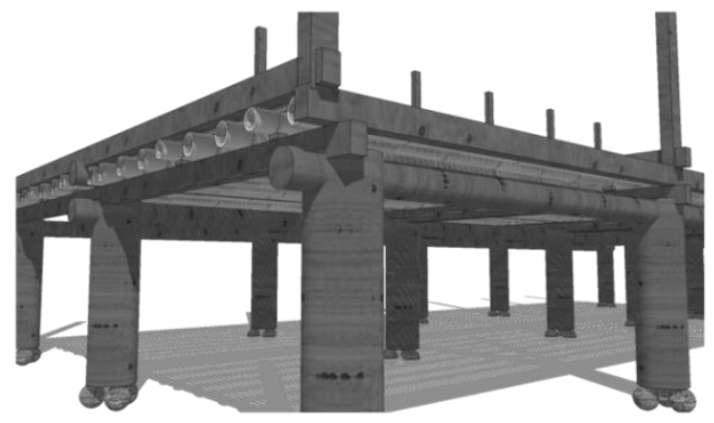

Gambar 9. Detail Sambungan Kolom dan Balok

Sistem pasak menggunakan sistem coak pada bagian kayu yang kemudian dikunci oleh pasak yang terbuat dari kayu. Pada bagian ujung kayu kemudian diberi sedikit ornamen dengan memberikan bentuk geometri sederhana pada bagian ujung kayu.

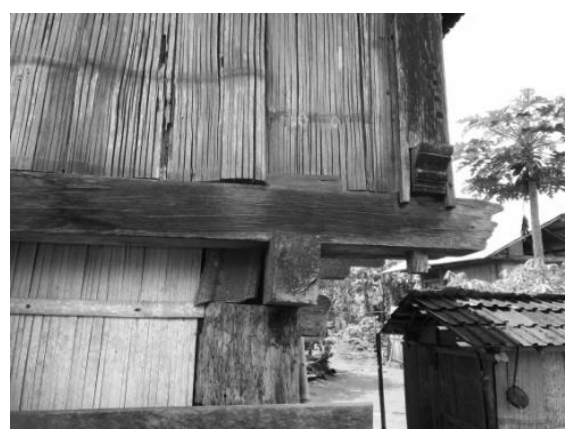

Gambar 10. Sambungan Kolom dan Balok tidak menerus

Struktur lantai dua tidak menerus dari lantai satu. Hal ini terlihat dari peletakan kolom yang tidak menerus dari lantai satu ke lantai dua. Hal ini kemungkinan dikarenakan pembangunan yang dilakukan secara bertahap. Namun belum ditemukan dengan jelas sistem peletakan kolom antara lantai satu dengan lantai 2 . 


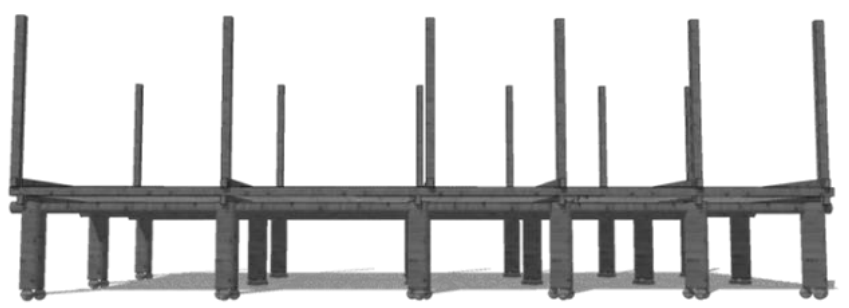

\section{Gambar 11. Sambungan Kolom dan Balok Tidak Menerus}

Sambungan kolom dan balok tidak menerus juga mungkin dipengaruhi oleh pembangunan yang memiliki sistem bertahap, dan juga karena memang sistem struktur di rumah tradisonal Pekon Hujung menggunakan sistem struktur meja.

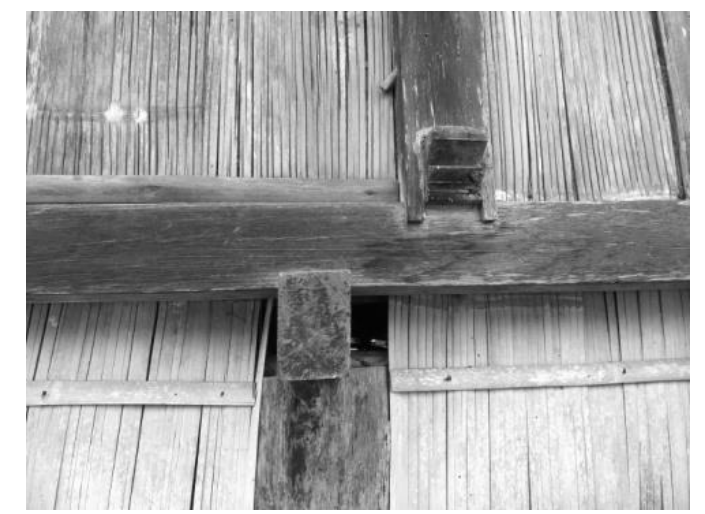

Gambar 12. Detail sambungan Kolom dan Balok Tidak Menerus

\section{SIMPULAN}

Rumah tradisional Desa Pekon Hujung Lampung apabila ditinjau dari sisi pengembangan ruang dari bentuk persegi menjadi ke bentuk seperti L, T, I dan bentuk laiinnya bertumbuh secara perlahan sesuai dengan penambahan kebutuhan ruang dikarenakan penambahan jumlah penghuni rumah. Apabila ditinjau dari sistem sambungan struktur secara keseluruhan menggunakan struktur dan konstruksi dari kayu dan merupakan sistem struktur yang paling efisien digunakan pada kawasan rawan gempa. Elemen bangunan yang dapat digunakan sebagai identitas Lampung adalah ukiran tanduk, bentuk atap lancip, dan adanya ruang beranda, dan rumah panggung. Jika dilihat dari kesimpulan maka sebagai saran kepada masyarakat yang berada pada kawasan rawan gempa untuk tetap mempertahankan sistem struktur kayu dalam pembangunan bangunan.

\section{UCAPAN TERIMA KASIH}

Ucapan Terima Kasih kami sampaikan kepada masyarakat dan pimpinan Pekon Hujung Lampung Barat, yang telah memberikan dukungan dalam terlaksananya penelitian ini. 


\section{REFERENSI}

Junianto, J. (2018). Penerapan Elemen Vernakular pada Perancangan Taman Krida Budaya Jawa Timur, Sebagai Proses Popular Vernakular, MINTAKAT: Jurnal Arsitektur, 19 (1), pp. 19-33.

Morgan, L. H. (1881). Houses and house-life of the American aborigines. US Government Printing Office.

Pangarsa, G. W. et al. (2012). 'Tipologi Nusantara Green Architecture Dalam Rangka Konservasi Dan Pengembangan Arsitektur Nusantara Bagi Perbaikan Kualitas Lingkungan Binaan', RUAS (Review of Urbanism and Architectural Studies), 10(2), pp. 78-94.

Sumalyo, Y. (1993). Arsitektur Kolonial Belanda di Indonesia. Gadjah Mada University Press.

Syarief, R. (2017). Pengaruh Warisan Budaya Perahu pada Arsitektur Tradisional di Lampung. Aura Publishing. 